\title{
Capacitive electrode sensor implanted on a printed circuit board designed for continuous water level measurement
}

\author{
Salami Ifedapo Abdullahi, Mohamed Hadi Habaebi, Noreha Abdul Malik \\ Department of Electrical and Computer Engineering, International Islamic University Malaysia (IIUM), Malaysia
}

\begin{tabular}{|c|c|}
\hline Article Info & ABSTRACT \\
\hline Article history: & \multirow{13}{*}{$\begin{array}{l}\text { Water level sensors are one of the practical ways to get the actual } \\
\text { measurement of the depth of a dam or canal. The ease of deployment and } \\
\text { easy data acquisition makes them widely used in many fields. Therefore, it } \\
\text { will be advantageous to have a miniaturized water level sensor for easier } \\
\text { mobility and deployment. A novel method for measuring water level using a } \\
\text { Printed Circuit Board has been proposed in this paper. The design stages of } \\
\text { circuit sketching, printing of sketch on PCB and etching are discussed for the } \\
\text { electrode water level sensor. A signal conditioning circuit is necessary to } \\
\text { maintain a steady flow of current from the power source. The fabricated } \\
\text { electrode water level sensor was tested based on its capacitive effect while } \\
\text { charging up and the amount of current at each electrode finger at the } \\
\text { saturation stage. The hardware enablers for this test were the multimeter and } \\
\text { LCR meter. Arduino microprocessor was used to test and measure the } \\
\text { transient response time for each electrode finger. The transient response } \\
\text { sensitivity of the electrode sensor is measured to be } 0.0873 \text { millisecond/cm } \\
\text { while the resolution of the electrode sensor is } 0.1 \mathrm{~cm} \text { over a range of } 30 \mathrm{~cm} \\
\text { water level. A multiple correlation of } 0.921 \text { was achieved for the water level, } \\
\text { measured current and measured capacitance with P-values less than } 0.05 \\
\text { indicating strength of the data obtained from the tests conducted. The result } \\
\text { showed strong evidence that the electrode water level sensor can be an } \\
\text { alternative method of measuring water level. }\end{array}$} \\
\hline Received Dec 14, 2018 & \\
\hline Revised Feb 1, 2019 & \\
\hline Accepted Feb 13, 2019 & \\
\hline & \\
\hline Keywords: & \\
\hline Capacitive electrode & \\
\hline Continuous water level sensor & \\
\hline Energy security & \\
\hline PCB water level sensor & \\
\hline Signal conditioning circuit & \\
\hline Water level sensor & \\
\hline & \\
\hline
\end{tabular}

Copyright $\odot 2019$ Institute of Advanced Engineering and Science. All rights reserved.

Corresponding Author:

Mohamed Hadi Habaebi,

Department of Electrical and Computer Engineering,

International Islamic University Malaysia (IIUM), Malaysia.

Email: habaebi@iium.edu.my

\section{INTRODUCTION}

This article is an extension of the work presented during the ICCCE'18 Conference in September 2018. This article provides more comprehensive details on the previous work as the study developed further by testing the performance and durability of the PCB level sensor. Water level sensors are based on a principal of height measurement using digital technology. Historically, water meters were used by farmers in Oases Ghadames which have existed for over 3000 years, proving that water level measurements were being used pre-civilisation era [1]. Water level sensors come in all shapes and sizes with different specifications and functions. There are two main types of water level sensors, they are contact and non-contact water level sensors. Non-contact, continuous level sensors include Ultrasonic sensors, Radar Level sensors and optical sensors. Contact, point level sensors include Float Switch, Capacitance sensor, Conductivity probes and Magnetic Level Gauges [2]. Water level measurements are now widely used for various things such as measuring the depth of rivers, tanks and irrigation of agricultural lands [3, 4]. In recent years, the use of optical fibers to measure water level has gradually increased. Optical fibers became a popular choice due to their application of the principle of light, light transmission and reflection of light to make a good sensor for measuring liquid height [5]. Gathered literature in [6-9] as shown that the principle of capacitance liquid 
level sensors is making use of the charge separation in a parallel plate which induces an internal electric field while the liquid acts as a dielectric which reduces the field and increases the capacitance realised at those specific points. Despite this, contact water level measurement has proven itself to be more resilient under vigorous conditions while being more cost-effective and offering a reasonable precision compared to contactless and optical fiber water level sensors.

Consecutively, capacitive type liquid level sensors were presented in various other papers while their wide acceptance in the market has shown to have significant impact in hydroponics, controlling material position and decomposition of multi-phase liquids as presented in [10-15]. Fiber Bragg Grating is an extension of optical fiber filter offering a higher precision with continuous level monitoring at the expense of having increased costs and the need for recalibration for different kinds of liquids [16]. [17] discussed on the usage of capacitive water sensor to measure water level in a controlled laboratory experiment. The core element of the electrode sensor are the electrode fingers which acts as interdigitated sensors to sense a slight change in capacitive effect due to the presence of aqueous liquid. Thus, this detection enables the continuous water level measurement of the electrode sensor. Furthermore, [18] had used fuzzy algorithm to determine the river water quality. By doing so, it eliminates the use of manual methods to get water tested by reducing the use of physical labour and lessening the possibility of human error. Genetic algorithm was embedded together with fuzzy system to make detection of water quality faster and simpler. [19] suggested an alternative means of benefiting from measuring flow of water by carrying out simulation with a turbine flow sensor. This method ensures continuous flow measurement to make sure rising water depth in a system can be sensed on time.

Consecutively, [20] designed a method to control liquid level in an industrial setting. The concept made use of fuzzy controller to optimize a system that can control non-linear processes of a water tank container. [21] made use of water level sensor to measure water level in a system built to manage flood disaster alert. Water level sensor were important in this study as it enabled an inexpensive way for water level monitoring to be achieved. [22] made a real-time monitoring of water height at different intervals. The system made use of a camera as a visual guide to support the water level monitoring system. The functionality of the system relies on both an android based graphical user interface which snap pictures at pre-set intervals to record the water level. This gave real time information of the water level and gives a visual image in case of a system breakdown. Since water level monitoring has been discussed elaboratively, it is mandator to relate the impact of weather condition on the measurement of water level. However, the rainfall pattern can also be measured with adequate set-up of water level monitoring tools and equipment. This will gather enough information which can be used to predict and reduce rain attenuation for Earth-Space Satellite communication [23]. The ability to collect adequate data of rainwater level would greatly help to identify geographical areas that are mostly affected by high amount of rain pour which could lead to unwanted rain attenuation.

Among the main advantages of capacitance liquid level sensors is their precision and stability in measuring liquid level and their low maintenance costs. This paper describes the design and testing of a water level measurement system based on a capacitive effect with parallel electrode fingers of uniformly increasing length on a printed circuit board (PCB). The capacitance between parallel electrode fingers on the printed circuit board depends on the water height. Similarly, as seen in Figure 1 showed the driven element which is the positive side of the plate and the sensing element which is the negative side of the plate as it creates a fringe effect, making the gap to be seen between the measured capacitance and calculated capacitance. Furthermore, it was important to fabricate a signal conditioning circuit to help in data acquisition process from each electrode finger as water rises above them. The electrode water level sensor has been thoroughly tested and proven to work efficiently under both static and dynamic conditions. Therefore,it is convincing that the water level sensor can be applied in implementing a flood monitoring system. The electrode sensor was tested on its capacitive effect while also making sure the laboratory experiment is carried on under a controlled condition. Arduino microcontroller was also used to test the efficiency of the water level sensor.

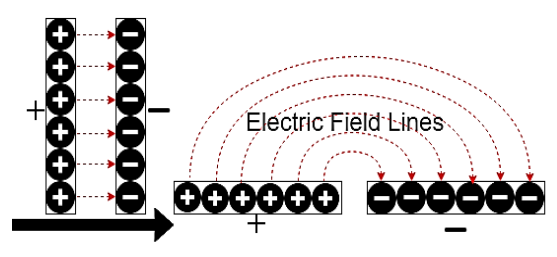

Figure 1. Working mechanism of two parallel capacitive electrode on a PCB 


\section{RESEARCH METHOD}

\subsection{PCB circuit design and fabrication of sensor}

The software enabler used is Microsoft Word 2010 Edition to sketch the circuit that will be imprinted on the PCB board which was used instead of more advanced circuit design software such as Eagle due to the simplicity of the circuit layout. Figure 2 shows the process undertaken for the fabrication of the sensor. The circuit layout was printed using a laser printer on a transparent A4 size paper and its specifications were used for measurement of the electrode fingers as shown in Figure 3(a). Then, the printed image was transferred onto a prepared FR-4 substrate PCB. The printed image was bonded onto the copper plate using a photoplatter machine, after which it was placed inside the UV insulator machine for 180 seconds to irradiate the PCB with UV light. The copper plate was removed from the UV insulator chamber and the printed image was removed from it. The copper was cleaned with photorevelator and rinsed with distilled water before it was submerged into a bowl of ferric chloride acid to etch the part destroyed by UV irradiation. The board is taken out after 15 minutes when all the unnecessary copper is etched away from the board. A fine sand paper was used to remove all insulating drawing materials used on the board leaving behind the electrode finger lines. Another copper plate was cut exactly with the same measurement as the copper electrode sensor was prepared to be used as the reference electrode.

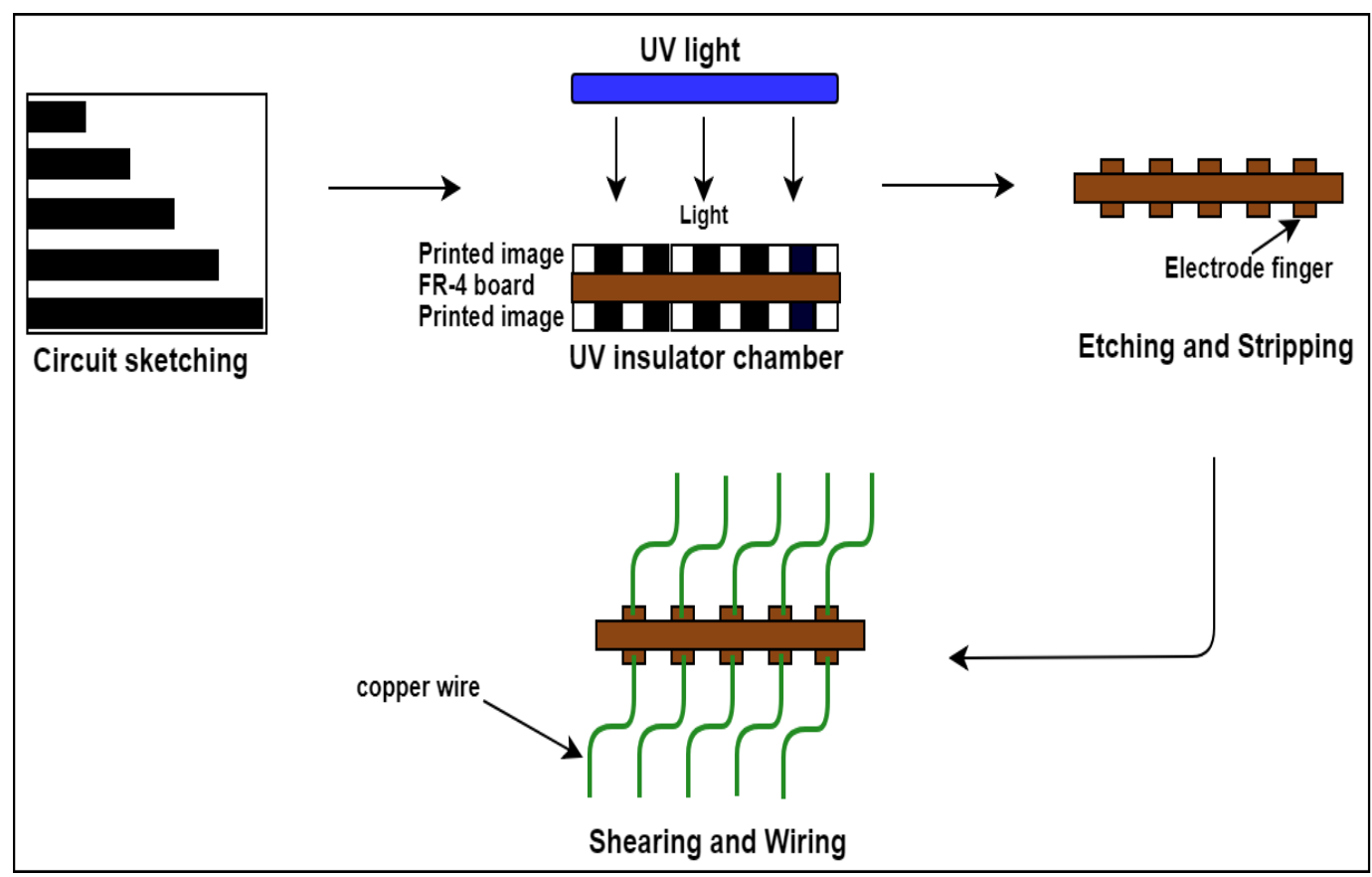

Figure 2. Process flow for the fabrication of electrode sensor

After the PCB sensor had been fabricated, single-core tinned copper wires of length $\sim 58 \mathrm{~cm}$ and diameter $0.055 \mathrm{~cm}$ were soldered to the top end of each electrode finger for data acquisition as shown in Figure 2. The electrode sensor and reference electrode have a height of $31 \mathrm{~cm}$, breadth of $2.7 \mathrm{~cm}$ and a width of $0.2 \mathrm{~cm}$. The average spacing between each electrode finger is $0.2 \mathrm{~cm}$ while the thickness of each one is 0.3 $\mathrm{cm}$. Each electrode finger was made to have an increasing length of $3 \mathrm{~cm}$ and the electrode sensor was built with 5 sensing electrodes on each side of the copper plate for a total of 10 water levels as shown in Figure 3(b) and Figure 3(c). This design reduces the number of copper plates that need to be used for a single sensor. Additionally, the electrode capacitive sensor in this paper took a few design features and specifications from previous work of Chetpattananondh et al. (2014) in the reference list of this article, including the length of 31 $\mathrm{cm}$ for the longest electrode finger. The width of the electrode sensor is fixed according to the manufacturer specifications for the PCB. The breadth was set to $2.7 \mathrm{~cm}$ in order to fit 5 electrode fingers on each side of the electrode sensor. 

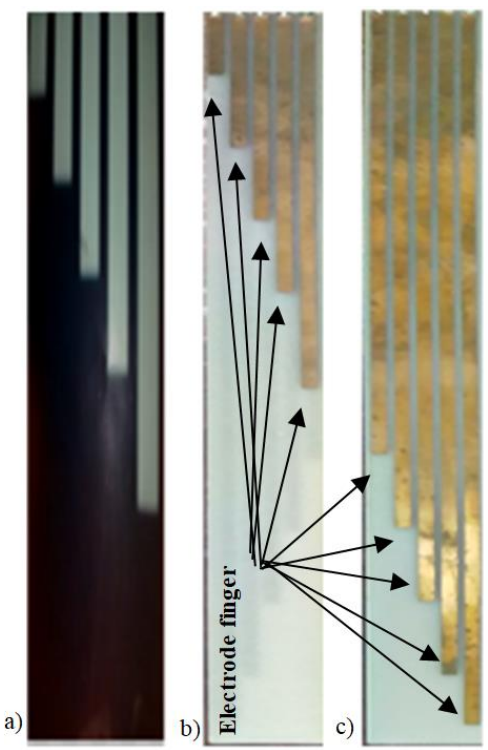

Figure 3. (a) Printed circuit on the transparent A4 size paper for illustration purpose only, (b) back-side of electrode sensor, (c) front-side of electrode sensor [17]

\subsection{Signal conditioning circuit design}

The signal conditioning circuit board was built to process the signal that comes from the sensing electrode and produce digital information that is understandable by the microprocessor. It consists of a pre-cut donut board with a fixed number of resistors, transistor and male connectors. The circuit consists of a total of 10 2N2222 NPN bipolar junction transistors for switching on the electrode sensor, plus 10x470 ohms resistors, 10x220 ohms resistors and 10x22000 ohms resistors soldered together to reduce current flow. 20 male connectors are used which enable the connection of the female connectors from the electrode wires coming from the sensing electrode sensor to accommodate connections to the microprocessor and the linking electrode wires. Figure 4(a) showed that 3 male connectors were specifically made for the connection of the reference electrode, input voltage and ground to the microprocessor. The signal conditioning circuit placed on the donut board has a length of $14.5 \mathrm{~cm}$, breadth of $6.3 \mathrm{~cm}$ and thickness of $0.2 \mathrm{~cm}$. The schematic diagram for the three-water level signal conditioning circuit with the reference electrode is shown at Figure 4(a) and a capture of the fabricated signal conditioning circuit is pictured at Figure 4(b).

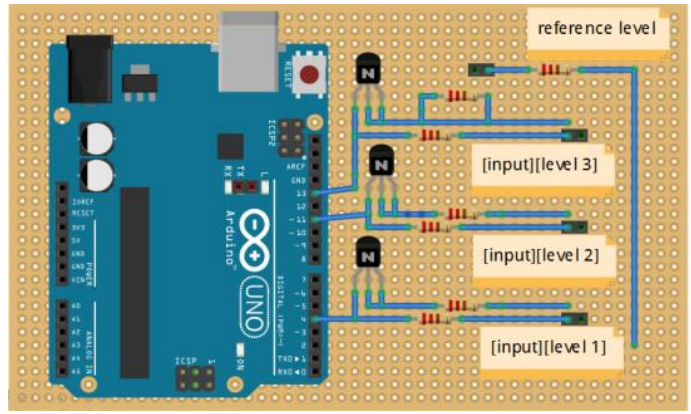

(a)

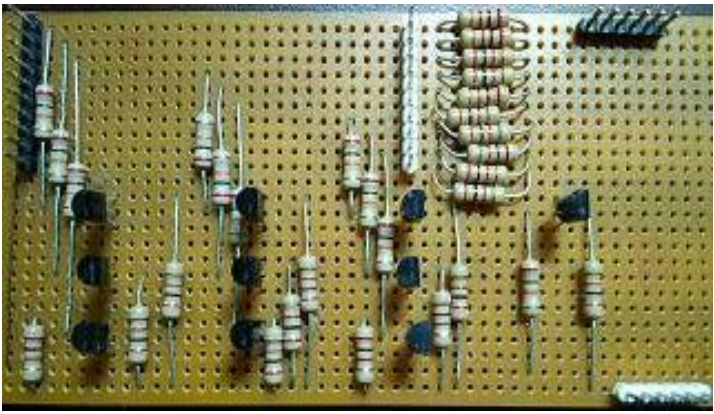

(b)

Figure 4. (a) the connection of signal conditioning circuit board to the microprocessor (Arduino Uno), (b) Fabricated signal conditioning circuit [17]

\subsection{Experimental setup and testing of electrode sensor}

The basic experimental set-up to measure the capacitance of the electrode sensor consists of a laboratory DC power supply, a digital multimeter, an LCR meter and a 5.5-liter plastic container with a height of $34 \mathrm{~cm}$ and diameter of $21 \mathrm{~cm}$. PVC pipe of height $34 \mathrm{~cm}$ and diameter of $2.8 \mathrm{~cm}$ was screwed in at

Capacitive electrode sensor implanted on a printed circuit board designed for ... (Salami Ifedapo Abdullahi) 
the bottom of the container to enable tap water to flow into the container. The two probes connected between the signal conditioning circuit and the DC power supply were done to provide power, while two other probes were used as a connection between the digital multimeter and the electrode finger under test. This configuration allowed the measurement of current at each electrode finger with a supply of only 5 volts from the DC power supply. The capacitance of each electrode finger is measured using the combination of the LCR meter, reference electrode and the electrode sensor as displayed in Figure 5. The experiment was carried out by firmly attaching the reference electrode and electrode sensor at opposite edges of the plastic container using double sided tape as adhesive, connecting two probes to the positive and negative input of the LCR meter, the positive end of the probe (red color) connected to the reference electrode and the negative end of the probe (black color) connected to each electrode finger being tested. The frequency chosen on the LCR meter is $1 \mathrm{Khz}$ and the mode of measure is in nano-farads.

Finally, the electrode sensors, signal conditioning circuit board and Arduino Uno were connected as in Figure 5 in order to calibrate the electrode sensor reading of the water level using the output voltage from each electrode finger transducer. The actual water levels were observed and marked on the container while the measured water levels were recorded by the Arduino Uno controller and read via the Arduino Serial monitor. Functional program code for the electrode sensor was written inside Arduino IDE. Additionally, an interrupt in the program code enabled the transient response time for each capacitive electrode finger to be measured. The experiment was repeated 5 times under a standardized environment for a fair comparison between the measured and actual water level readings. Table 1 shows the permittivity and conductivity of tap water and FR-4 substrate.

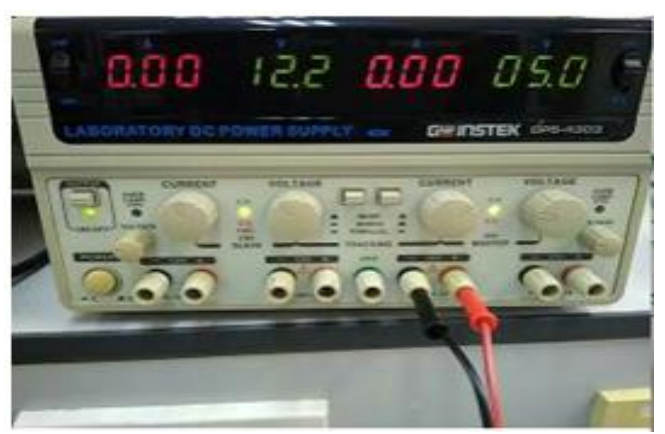

(a)

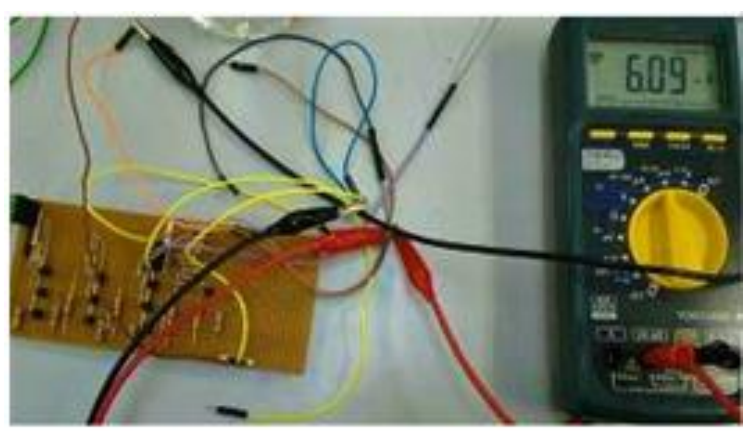

(b)

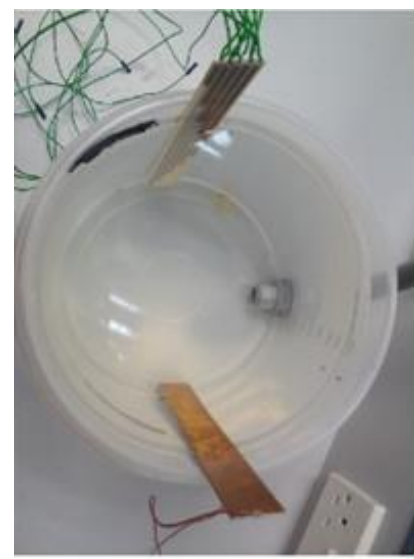

(c)

Figure 5. (a) DC power supply, (b) Signal conditioning circuit connected to digital multimeter, (c) Set-up for measuring capacitance [17]

Table 1. Permittivity and conductivity of dielectric material

\begin{tabular}{cc}
\hline Dielectric Material & Permittivity(Farad $/ \mathrm{m})$ \\
\hline Tap Water & 80 \\
FR-4 substrate & 4.4 \\
\hline
\end{tabular}




\section{RESULTS AND ANALYSIS}

Figure 6 showed the electrode water level sensor under evaluation which each electrode finger current was compared with water level. Under the same settings, Figure 7 showed the capacitance of each electrode finger as it was compared with water level. A steady increment of measured current from $23 \mathrm{nA}$ to $61.1 \mathrm{nA}$ was observed as water level is gradually increased from $0 \mathrm{~cm}$ to $30 \mathrm{~cm}$. the result also showed that the measured capacitance rises from $0 \mathrm{nF}$ to $13.605 \mathrm{nF}$ in an incremental order when water level gradually increased from $0 \mathrm{~cm}$ to $15 \mathrm{~cm}$ but the readings plunged and kept an unsteady pattern in the graph from $4.949 \mathrm{nF}$ to $5.629 \mathrm{nF}$ as water level increased from $15 \mathrm{~cm}$ to $30 \mathrm{~cm}$ at an increasing pace. Accidental parasitic capacitive coupling between the electrode fingers of water level from $15 \mathrm{~cm}$ to $30 \mathrm{~cm}$ can caused this to occur. The measured capacitance is noisy and lessened because of the capacitive coupling that occurs in this period. This is an effect that can be reduced by separating the electrode fingers significantly or by adding a line electrode in between the electrode fingers which keeps the electrode fingers capacitively coupled to the ground rather than to each other. Alternatively, the effects of capacitive coupling can be diminished by placing a decoupling capacitor between the input voltage and the reference voltage. High impedance which is supposed to be decreasing as the water level increases from $15 \mathrm{~cm}$ to $30 \mathrm{~cm}$ might be another potential reason for the huge drop in the measured capacitance.

The relationship between current (i) and capacitance (C) is showed in (1) and (2) illustrating clearly that each electrode finger capacitor and the reference capacitor were being charged $(\mathrm{Q})$ until they reached the maximum supplied voltage $(\mathrm{V})$ of the DC power supply in function of time $(\mathrm{t})$.

$$
\begin{aligned}
& Q=C \times V \\
& i=C \frac{d v}{d t}
\end{aligned}
$$

A mathematical expression to manually calculate the capacitance for each electrode finger is depicted in (3) as provided in Mamishev et al.(2004).

$$
C=\varepsilon_{0} \varepsilon_{r} \frac{2 n x h}{w}
$$

where $\varepsilon_{0}$ is the permittivity of free space, $\varepsilon_{r}$ is the permittivity of water, $\mathrm{n}$ is the number of electrode fingers, $x$ is the overlap length, $h$ is the electrode height and $w$ is the space between electrodes. The regression analysis for the measured data from the experimentation done on the electrode water level sensor was carried out using MedCalc statistical software. The results gave a multiple correlation coefficient of 0.9210 with the measured current readings having a P-value of 0.0002 and the measured capacitance readings having a $\mathrm{P}$-value of 0.0140 . The multiple correlation coefficient uses the best linear predictors that are indicative of a higher predictability of water level reading from the measured data while $\mathrm{P}$-values $<0.05$ are indicative of very good explainable variations between the values of the measured data.

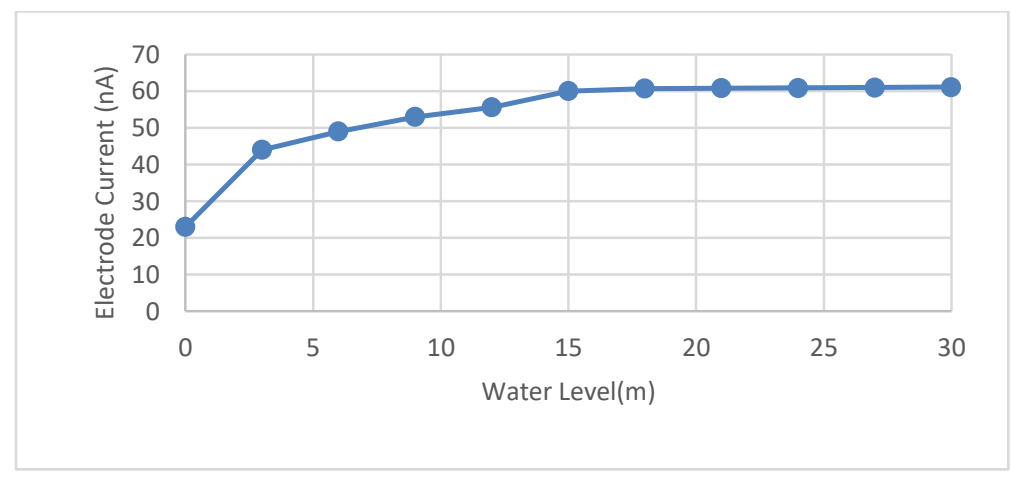

Figure 6. Experimental result of measured current as a function of water level [17] 


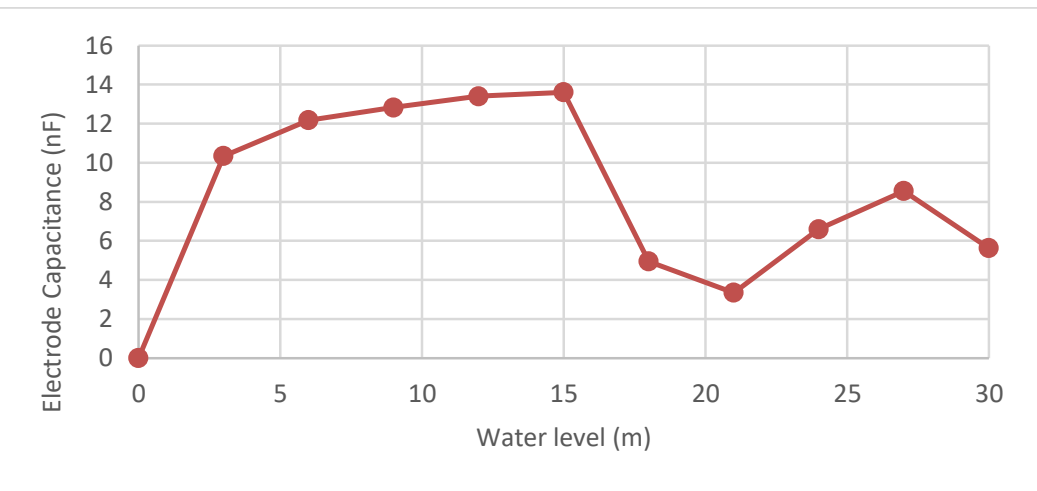

Figure 7. Experimental result of measured capacitance as a function of water level [17]

The linearity test was conducted by observing and comparing the deviation between the measured water level and actual water level (Figure 8). The minimum error is $0 \mathrm{~cm}$ when there is no presence of water and the maximum error is $0.3 \mathrm{~cm}$ when water level is $30 \mathrm{~cm}$. The mean error is $0.1 \mathrm{~cm}$ over the level range of $30 \mathrm{~cm}$. The reason for this linearity error might be because of the non-uniformity of electric field at the end of the electrode. Other factor that might add to this error might be due to the program code inability to differentiate between closely related measured variables that corresponds to different levels. The transient response is a measure of how fast the electrode capacitor charges up voltage. Therefore, Figure 9 showed the relationship of the water level in function of recorded response time of each electrode finger. The mean response time is 2.073 milliseconds which showed that the electrodes charges up fast in response to supplied voltage. (4) shows the mathematical expression of transient response in terms of a resistor $(\mathrm{R})$ in series with a capacitor $(\mathrm{C})$ and the response time $(\tau)$ which is measured in seconds. Linear regression of actual water level and transient response were examined as shown in Figure 10. Coefficient of determination $\left(R^{2}\right)$ produced a value of 0.8666 with a $\mathrm{P}$-value of 0.004 which shows strong relationship between the data. (5) validates the linear least square expression of the response time against water level. The sensitivity is 0.0873 milliseconds/cm with an offset error of 0.763 due to processing time of the microcontroller.

$$
\begin{aligned}
& \tau=R \times C \\
& y=0.0873 x+0.763
\end{aligned}
$$

where $\mathrm{y}$ is response time and $x$ is water level.

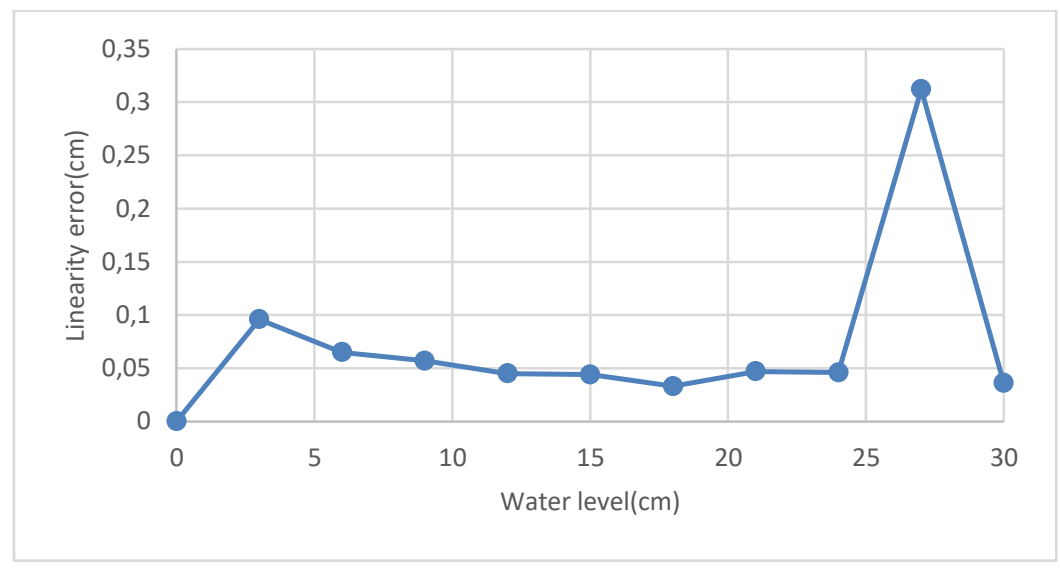

Figure 8. Experimental result of linearity error against water level 


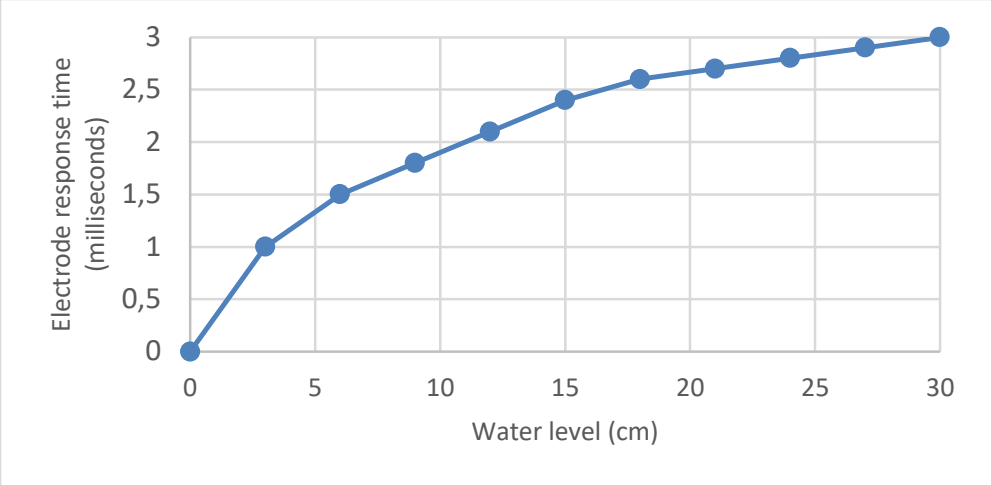

Figure 9. Experimental result of sensor response time against water level

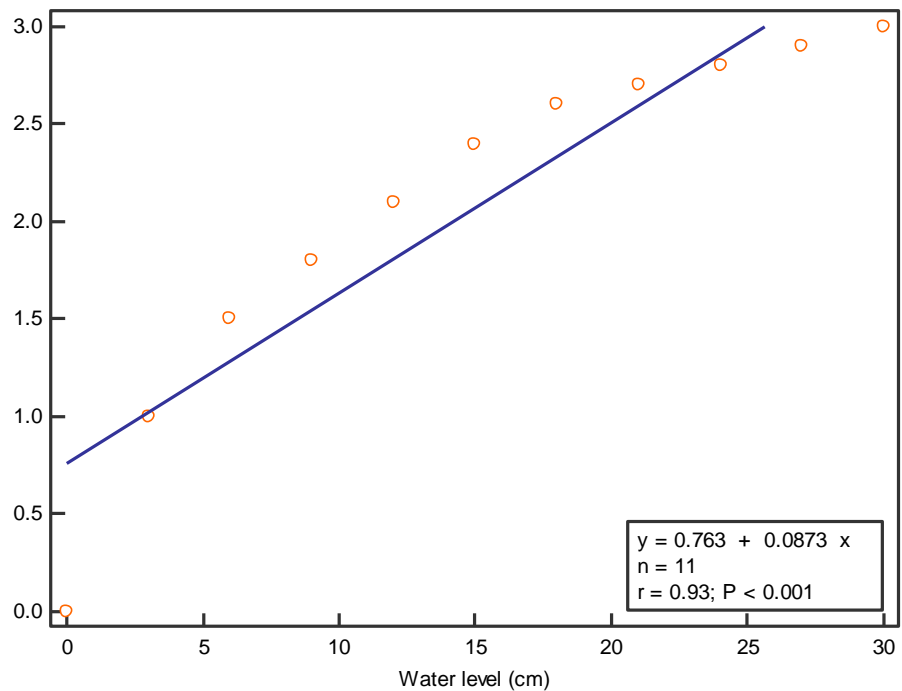

Figure 10. Fitting curve to the experimental data by regression line

The minimum input voltage for the electrode sensor is 2.5 volts while the microprocessor output 5 volts. Hence, this means that the electrode sensor used a limited amount of voltage. The maximum current that Arduino can withstand is $200 \mathrm{~mA}$ while the electrode sensor maximum dissipated current is $61.1 \mathrm{nA}$ which is reasonably lower than the Arduino threshold. In addition, when there is no presence of water, the electrode sensor only seeps 1.035 volts which means it uses little voltage when it is in idle state. The electrode sensor measured resistance was measured to be 5.5 kilo-ohms when there is water while the resistance is infinity when there is no water. The power consumed by the electrode sensor is $30.3 \mathrm{~mW}$ when the voltage utilised is 5 volts. As the electrode sensor make use of the conductivity of tap water to measure water level, over a long period of time the copper plate will start to decay slowly. Lastly, the electrode sensor has been tested in a flood simulation environment in Abdullahi, Habaebi, Gunawan \& Islam (2017) and it has proven to be effective in practical experimental test.

\section{CONCLUSION}

A capacitive sensor that can measure water level is very important as it continuously measures water level with the increase in volume of water. This makes them to be able to detect even a slight increment in water level as the mode of measurement is based on the capacitive effects and current measurements from each electrode finger. This paper has been able to develop a novel electrode water level sensor which is able to measure water level from $0 \mathrm{~cm}$ up until $30 \mathrm{~cm}$ in height. Electrode finger which act as an electrode traces allowed the readings of water level which have a mean offset error of $0.1 \mathrm{~cm}$. Tap water was the only means for the testing of this electrode water level sensor but it's usage can be extend to other non-viscous liquids. A 
1 millisecond mean response time for the electrode sensor showed that it is relatively fast to detect water presence as well as it is sensitive to small changes in water level. The electrode water level sensor is built to be compact and light to enable easier deployment in areas where large water level sensors are not applicable. The electrode water level remains functional while it is also effective at taking fine measurements of level rise of liquid substances. In the future, it will be advantageous for further testing of the electrode water level to be applied to different liquids and mixture that exist in chemical plants.

\section{ACKNOWLEDGEMENTS}

This work was conducted at the IOT and Wireless Communication Protocols Lab, and is partially funded by IIUM Publication RIGS grant no. P-RIGS19-003-0003 and the Malaysian Ministry of Education (MOE) research fund No. FRGS16-067-0566.

\section{REFERENCES}

[1] Awwa Meter Manual, "Chapter I-Early History of Water Measurement and the Development of Meters," Journal (American Water Works Association), vol 51, no. 6, pp. 791-799, June 1959.

[2] A. V. Mamishev, K. Sundara-Rajan, Fumin Yang, Yanqing Du and M. Zahn, "Interdigital sensors and transducers," in Proceedings of the IEEE, vol. 92, no. 5, pp. 808-845, May 2004. doi: 10.1109/JPROC.2004.826603

[3] Abdullahi, S. I., Habaebi, M. H., Gunawan, T. S., \& Islam, M. R., "Miniaturized Water Flow and Level Monitoring System for Flood Disaster Early Warning," In IOP Conference Series: Materials Science and Engineering, vol. 260, no. 1, pp. 012019, November 2017.

[4] A. Manut, A. S. Zoolfakar, N. A. Muhammad and M. Zolkapli, "Characterization of Inter Digital capacitor for water level sensor," 2011 IEEE Regional Symposium on Micro and Nano Electronics, Kota Kinabalu, 2011, pp. 359-363. doi: 10.1109/RSM.2011.6088360

[5] Loizou, K., \& Koutroulis, E., "Water level sensing: State of the art review and performance evaluation of a low-cost measurement system," Measurement, vol. 89, pp. 204-214, July 2016.

[6] Chetpattananondh, K., Tapoanoi, T., Phukpattaranont, P., \& Jindapetch, N., "A self-calibration water level measurement using an interdigital capacitive sensor," Sensors and Actuators A: Physical, vol. 209, pp. 175-182, 2014.

[7] Quoc, T. V., Dac, H. N., Quoc, T. P., Dinh, D. N., \& Duc, T. C., "A printed circuit board capacitive sensor for air bubble inside fluidic flow detection. Microsystem Technologies," vol. 21, no. 4, pp. 911-918, 2015.

[8] A. S. Zoolfakar, S. B. Hashim, M. Zolkapli and M. F. Idros, "Design, fabrication and characterization of conductivity sensor using printed circuit board," 2010 6th International Colloquium on Signal Processing \& its Applications, Mallaca City, 2010, pp. 1-6. doi: 10.1109/CSPA.2010.5545334

[9] Azman, M. F., Yahya, A., \& Purwanto, H., "Effect of Numbers of Fringing Electric Field (FEF) Fingers on the Performance of Sensor for Water Content in Soil," International Journal of Materials, Mechanics and Manufacturing, vol. 1, no. 1, pp. 46-49, 2013.

[10] Rajapaksha, R. D. A. A., Hashim, U., \& Fernando, C. A. N., "Design, fabrication and characterization of $1.0 \mu \mathrm{m}$ Gap Al based interdigitated electrode for biosensors," Microsystem Technologies, vol 23, no. 10, pp. 4501-4507, 2017.

[11] Gong, C. S. A., Chiu, H. K., Huang, L. R., Lin, C. H., Hsu, Z. D., \& Tu, P. H. (2016). Low-cost comb-electrode capacitive sensing device for liquid-level measurement. IEEE Sensors Journal, 16(9), 2896-2897.

[12] Nishimura, T., Okuyama, Y., Matsushita, A., Ikeda, H., \& Satoh, A. (2017, October). A compact hardware design of a sensor module for hydroponics. In Consumer Electronics (GCCE), 2017 IEEE 6th Global Conference on (pp. 1-4).

[13] Paczesny, D., Tarapata, G., Michał, M., \& Jachowicz, R., "The capacitive sensor for liquid level measurement made with ink-jet printing technology," Procedia engineering, vol. 120, pp. 731-735, 2015.

[14] Ibrahim, D., "Development of a low-cost educational liquid-level sensor circuit," International Journal of Electrical Engineering Education, vol. 52, no. 2, pp.168-181, 2015.

[15] C. S. S. Babu and P. Manohar, "Design of a low cost signal conditioning circuit for self-compensated non contact capacitive type multi threshold liquid level sensor," International Conference on Circuits, Communication, Control and Computing, Bangalore, 2014, pp. 58-63. doi: 10.1109/CIMCA.2014.7057757

[16] M. Shao, X. Qiao, X. Zhao, Y. Zhang and H. Fu, "Liquid Level Sensor Using Fiber Bragg Grating Assisted by Multimode Fiber Core," in IEEE Sensors Journal, vol. 16, no. 8, pp. 2374-2379, April 15, 2016.

[17] Abdullahi, S. I., Habaebi, M. H., \& Malik, N. A., "Capacitive Electrode Sensor: Design and Testing," In 2018 7th International Conference on Computer and Communication Engineering, 2018, pp. 34-37.

[18] Kotimah, Q., Mahmudy, W. F., \& Wijayaningrum, V. N., "Optimization of Fuzzy Tsukamoto Membership Function using Genetic Algorithm to Determine the River Water," International Journal of Electrical and Computer Engineering, vol. 7, no. 5, pp. 2838-2846, 2017.

[19] Abdullahi, S. I., Malik, N. A., Habaebi, M. H., \& Salami, A. B., "Miniaturized Turbine Flow Sensor: Design and Simulation," In 2018 7th International Conference on Computer and Communication Engineering, 2018, pp. 38-43. 
[20] Vijayan, S., \& Avinashe, K. K., "Soft Computing Technique and Conventional Controller for Conical Tank Level Control," Indonesian Journal of Electrical Engineering and Informatics (IJEEI), 4(1), 65-73, 2016.

[21] Abdullahi, S. I., Habaebi, M. H., \& Malik, N. A., "Flood Disaster Warning System on the go," In 20187 th International Conference on Computer and Communication Engineering, 2018, pp. 258-263.

[22] Arboleda, E. R., Cero, C. D. L., \& Ala, K. J. L., "Android Application for Microcontroller-based Reservoir Water Level Monitoring. Indonesian Journal of Electrical Engineering and Informatics, vol. 6, no. 1, pp. 79-85, 2018.

[23] Rafiqul, I. M., Lwas, A. K., Habaebi, M. H., Alam, M. M., Chebil, J., Mandeep, J. S., \& Zyoud, A., Analysis of Time Diversity Gain for Satellite Communication Link Based on Ku-Band Rain Attenuation Data Measured in Malaysia. International Journal of Electrical and Computer Engineering, vol. 8, no. 4, pp. 2608-2613, 2018.

\section{BIOGRAPHIES OF AUTHORS}
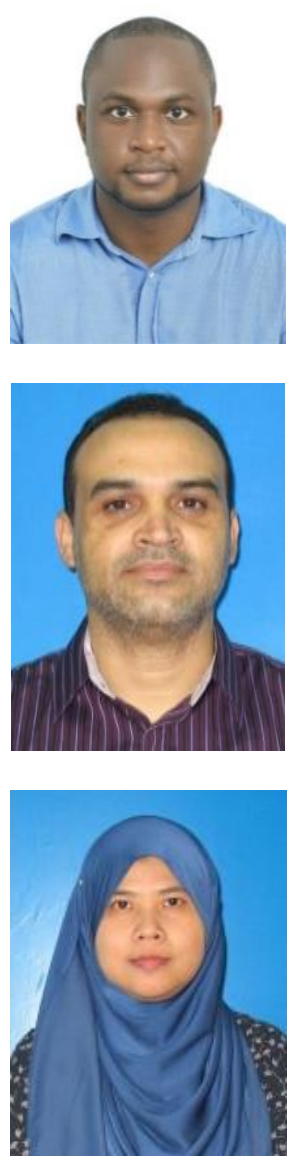

Abdullahi Salami recently acquired his Bachelor's degree in Telecommunication Engineering from International Islamic University Malaysia in 2018 and he is pursuing his Master in Telecommunication Engineering in International Islamic University Malaysia. His research interests are towards the fields of Telecommunications, Internet of Things, Data Analytics and Electronics. E-mail address:abdusalife@gmail.com

Mohamed Hadi Habaebi is with the department of electrical and Computer Engineering, International Islamic University Malaysia. His research interests are in IoT, wireless communications and Networking.

Noreha Abdul Malik received her BEng in Medical Electronics from University of Technology Malaysia (2001) and later pursued her MEng in Communication and Computer Engineering at National University of Malaysia (2004). She later received her PhD in Electronics and Electrical Engineering from University of Southampton, United Kingdom (2011). She is currently an assistant professor at International Islamic University Malaysia (IIUM). Her research interests are in biomedical signal processing and biomedical applications. She is a member of Institute of Engineers Malaysia (IEM) and Board of Engineer Malaysia (BEM). 